\title{
Circadian locomotor activity in the Virginia opossum
}

\author{
DONNA M. CONE* \\ Lynchburg College, Lynchburg, Va. 24504
}

The locomotor activity of two Virginia opossums was measured under D 24 and LD 12:12 conditions. Ss were inactive during the day and displayed two peaks of activity at night. The length of the activity period was approximately $24 \mathrm{~h}$. Under LD 12:12 the nocturnal cycle was more pronounced than under D 24. The period length and topography of the opossum's locomotor activity cycle are comparable to those obtained from other nocturnal mammals under similar lighting conditions.

Cone \& Cone (1968) demonstrated that Virginia opossums were more active between 10:00 p.m. and midnight than between 10:00 a.m. and noon. In addition, nighttime activity was significantly higher in the dark and under ambient illumination levels of 1 and $2 \frac{1}{2} \mathrm{fc}$ than it was under illumination levels of 5, 25, and $50 \mathrm{fc}$. These two observations indicate that the opossum is nocturnal. The purpose of the present study was to describe the topography of the opossum's locomotor activity pattern and specify its period length under conditions of constant darkness (D 24) and alternating light and darkness (LD 12:12)

\section{METHOD \\ Subjects}

Two opossums, one male and one female, served as Ss. They weighed about $750 \mathrm{~g}$ and were 3 months out of the pouch at the beginning of the study. Both had been gentled. Prior to the beginning of the experiment, the Ss had lived in individual cages in a colony room automatically maintained on LD 12:12. Throughout the experiment, they were maintained on an ad lib diet of Purina dog chow, meat, fruit, and water.

\section{Apparatus}

Each $S$ lived in a $61 \times 43 \times 43 \mathrm{~cm}$ wooden tilt box. A microswitch was mounted at each end of the tilt box, and electronic equipment was programmed so that depression of either microswitch yielded one count. These counts were automatically recorded hourly on electromechanical counters and on a BRS Foringer printout counter. The tilt boxes were placed on a sturdy platform and separated from each other by a partition. A foodwell was mounted inside each box at the central pivot point on one side. A water-bottle spout protruded through a small hole directly opposite the foodwell. The parallel metal bars of the box floor allowed fecal material to fall into sawdust-filled pans. The ambient temperature of the test chamber remained stable at $73^{\circ} \mathrm{F} \pm 3^{\circ}$ throughout the experiment. Continuous white noise of approximately $85 \mathrm{~dB}$ was presented by a small speaker mounted above each tilt box.

\section{Procedure}

At varying times on every third day, $E$ entered the test room, added food and water, and changed the waste pans. During dark conditions, $E$ turned off all lights in the area of the test chamber

*Thanks to Sidney L. Sanders and Lila Goodson for help in collecting and analyzing the data. and entered using a dim flashlight covered with red masking tape.

During the LD 12:12 condition, approximately $15 \mathrm{fc}$ of light was automatically presented daily from 6:00 a.m. to 6:00 p.m. DST by a houselight centrally mounted over each cage. Tissue-paper filters assured that this light was diffuse.

\section{RESULTS}

Figures 1 and 2 present the combined mean raw data for both opossums for four consecutive 12-day replications.

Figure 1 contains an hourly plot of the mean activity under the two D 24 replications. In Replication 1, there were less than 5 counts per hour between 8:00 a.m. and 6:00 p.m. A small secondary peak of 12 counts was reached at 7:00 p.m., followed by a drop to 6 counts at 9:00 p.m. Between midnight and 6:00 a.m., the mean hourly count ranged from 18 to 28 counts. In Replication 2, activity was below 5 counts per hour between 7:00 a.m. and 2:00 p.m. A sharp linear rise began after 2:00 p.m., reaching a secondary peak at 7:00 to $8: 00$ p.m. The major peak of 20 counts was reached between 1:00 and 3:00 a.m. As in Replication 1, the primary peak period was followed by a sharp linear drop in activity.

Figure 2 contains an hourly plot of the mean activity under two 12-day replications of the LD 12:12 condition. During Replication 3, there were less than 5 counts per hour from 7:00 a.m. to 5:00 p.m. A gradual linear rise began during the last hour of light, and a major peak of 26 counts was reached between 11:00 p.m. and midnight. This peak hour of responding was followed by a sharp drop in activity, with a secondary peak at 5:00 a.m.

In Replication 4 the low responding period remained at 7:00 a.m. to 5:00 p.m., and the peak responding remained at 11:00 p.m. to midnight. The magnitude of this peak was roughly half what it was under Replication 3, while the secondary peak at 5:00 a.m. increased slightly.

The period length was estimated by a periodogram analysis suggested by Enright (1965). This procedure involves fitting the data into artificially constructed period estimates until the range of the means is maximized. For the male opossum, the period length was $23.6 \mathrm{~h}$ for Replications 1,2 , and 3 and $23.8 \mathrm{~h}$ for Replication 4. The female opossum's period length was more variable, being $23.8 \mathrm{~h}$ for Replication $1,23.5 \mathrm{~h}$ for Replication 2, $23.7 \mathrm{~h}$ for Replication 3, and $24.6 \mathrm{~h}$ for Replication 4.

\section{DISCUSSION}

The present study has demonstrated that a free-running nocturnal activity pattern persists for at least 24 days in Virginia opossums moved from an LD 12:12 colony room to constant 


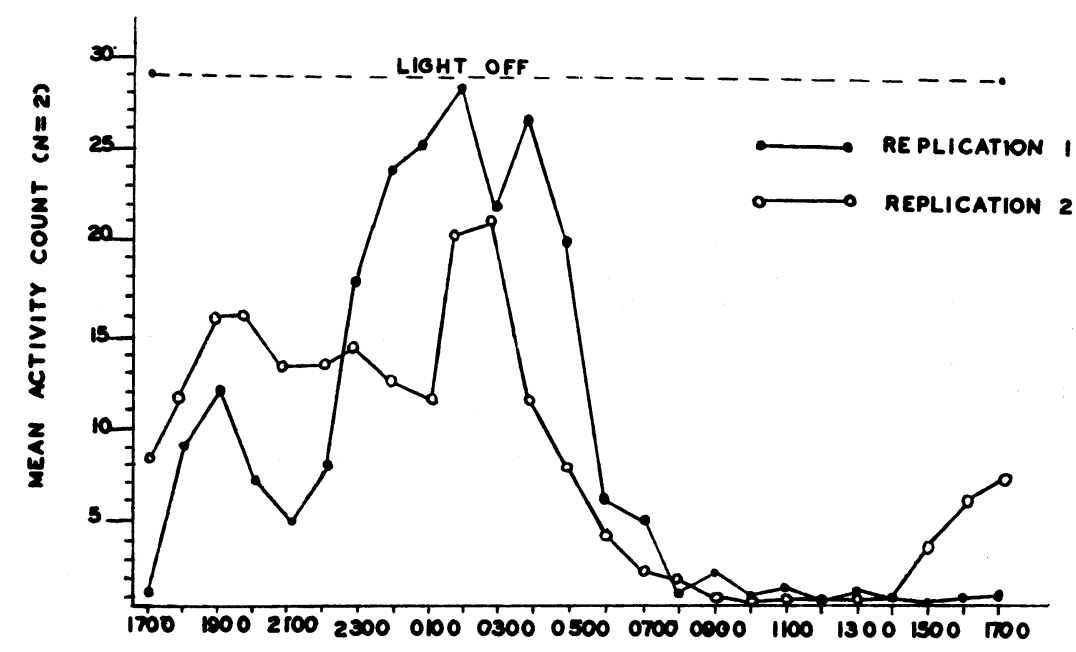

Fig. 1. Twenty-four-hour cage activity in the opossum under D 24.

\section{HOURS}

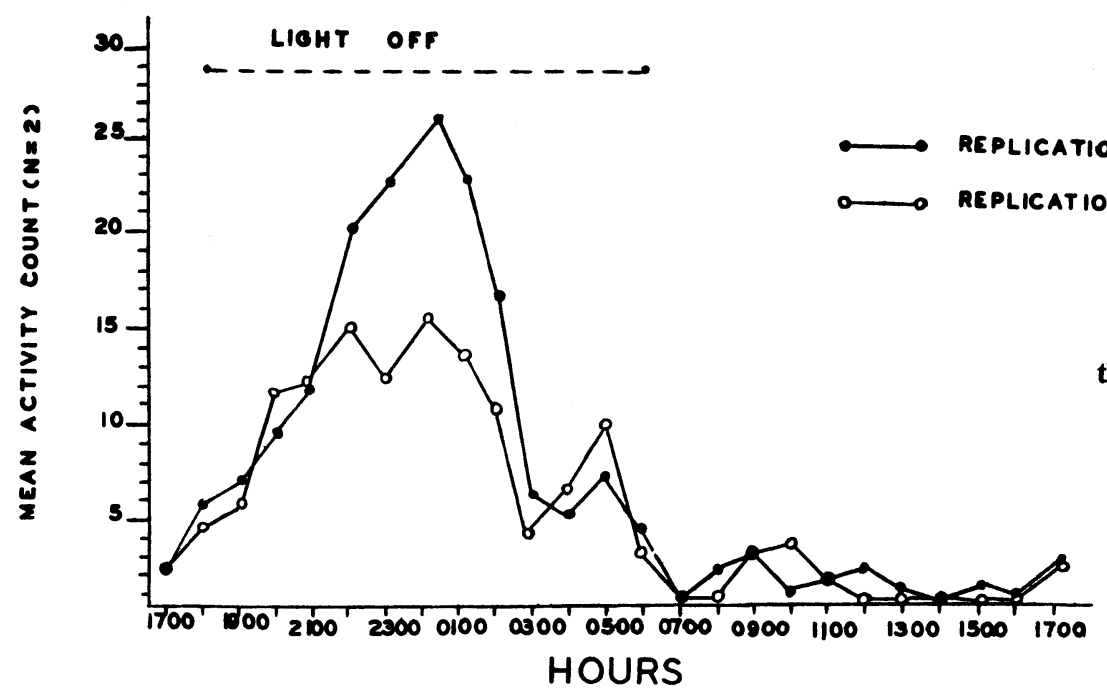

Fig. 2. Twenty-four-hour cage activity in the opossum under LD 12:12.

darkness. The period length is circadian (i.e., about $24 \mathrm{~h}$ ), with inactivity during the day and two peak periods of activity during the night.

The major effect of the addition of light was to accentuate the nocturnal cycle. Peak responding under LD 12:12 occurred at midnight, exactly halfway through the dark period, while it had occurred an hour later under D 24. In addition, the period of inactivity under LD 12:12 lasted for the entire light period, while it lasted only 9 or $10 \mathrm{~h}$ under D 24 . The topography of the activity under LD 12:12 is quite similar to that obtained by Tribukait (1956) for the domestic mouse.

In a review of the literature on activity rhy thms in mammals, Cloudsley-Thompson (1961) stated that most animals studied, including nocturnal rodents, display two activity peaks. In addition, the activity period is rarely exactly $24 \mathrm{~h}$ long, being $23.2 \mathrm{~h}$ in the mouse, for example. In terms of both topography and period length, the opossum's locomotor activity resembles closely that obtained for other nocturnal mammals.

\section{REFERENCES}

Cloudsley-Thompson, J. L. Rhythmic activity in animal physiology and behavior. New York: Academic Press, 1961. Cone, D. M \& Cone, A. L. Cage activity in the Virginia opossum. Psychonomic Science, 1968, 10, 259-260.

Enright, J. T. Accurate geophysical rhythms and frequency analysis. In J. Aschoff (Ed.), Circadian clocks. Amsterdam: North-Holland Publishing Company, 1965. Pp. 31-43.

Tribukait. B. Die Aktivitatsperiodik der weissen Maus im Kunsttag von 16-19 Stunden Lange Zeitschrift für Vergieichende Physiologie, 1956, 38, 479-490. Cited by $P$. Marler and W. J. Hamilton (Eds.), Mechanisms of animal behavior. New York: Wiley, 1966. P. 48

(Received for publication September 28, 1972.) 